\title{
Lasiodiplodia theobromae causes vascular streak dieback (VSD)-like symptoms of cacao in Davao Region, Philippines
}

\author{
Dionisio G. Alvindia ${ }^{1,2}$ • Frances Luisa M. Gallema ${ }^{1,2}$
}

Received: 15 May 2017 / Accepted: 19 September 2017 /Published online: 24 September 2017

(C) Australasian Plant Pathology Society Inc. 2017

\begin{abstract}
Samples of Theobroma cacao seedlings and mature trees with vascular streak dieback (VSD)-like symptoms were observed in Davao, Philippines in 2014. The symptoms were chlorosis and later necrosis of leaves, mostly those second or third from the stem tips. Abscission of these leaves occurred within 2 or 3 days of the first appearance of symptoms. Swelling of lenticels was distinct on the bark surface throughout the affected region. Cultural and morphological examinations and PCR assays revealed that the fungus associated with symptomatic leaves and branches was Lasiodiplodia theobromae. Pathogenicity was demonstrated by inoculation of healthy seedlings with a spore suspension of $L$. theobromae. This is the first report of $L$. theobromae as causal-pathogen of VSD-like symptoms in the Philippines.
\end{abstract}

Keywords Lasiodiplodia theobromae.VSD-like symptoms·cacao'pathogenicity

Recently, cacao (Theobroma cacao) growing in the Philippines is making a comeback because of the increasing local and global demand for dried fermented cacao beans. A target production of 100,000 t of dried, fermented cocoa beans by 2020 has been set by the Philippine government.

Dionisio G. Alvindia

dgalvindia@yahoo.com

1 Philippine Center for Postharvest Development and Mechanization (PHilMech), 3120 Science City of Muñoz, Nueva Ecija, Philippines

2 De La Salle University, 2401 Taft Avenue, 1004 Manila, Philippines
The most important diseases of cacao in the Philippines are VSD [caused by Ceratobasidium theobromae (syn. Oncobasidium theobromae) (Samuels et al. 2012)] and black pod rot [caused by Phytophthora palmivora (Guest 2007)] (www.bar.gov.ph/index.php/agfishtech-home/ crops/206-plantation-crops/1278-cacao-con-t). VSD was recognized in 1982 by Bourke (1992) in the province of Zamboanga del Sur, Mindanao Island (geographical coordinates: 7.851, 123.576) and has been reported occurring in southern Philippines (Guest and Keane 2007). VSD was likewise recorded as a major problem in the commercial plantations of South and Southeast Asia, Melanesia, China and India (Samuels et al. 2012; Guest and Keane 2007).

In February 2014, VSD-like symptoms were observed on seedlings and mature cacao trees at the nursery and bud wood gardens of the Cocoa Foundation of the Philippines (CocoaPhil) in Tugbok District, Davao, Philippines (geographical coordinates: $7.517,125.485)$. The symptoms were chlorosis and later necrosis of leaves, mostly those second or third from the stem tips. Abscission of these leaves occurred within 2 or 3 days of the first appearance of symptoms. Swelling of lenticels was distinct on the bark surface throughout the affected region. The apical and older leaves remained attached as the affected leaves abscised (Fig. 1). Visible dark streaks within the vascular tissue were conspicuous upon splitting the infected stems (Fig. 2). Moreover, three darkened vascular traces were evident at the base of the petiole and at the origin of the fallen chlorotic leaves whilst swelling of the lenticels was distinct on the bark surface on those regions of the stems/ branches which were affected (Fig. 3).

Infected leaves and stems were collected and cut into pieces $(20 \times 20 \mathrm{~mm})$, surfaced sterilized by dipping in $2 \%$ sodium hypochlorite solution for $2 \mathrm{~min}$, rinsed 3 times in sterile distilled water, blotted dry on sterile filter paper 

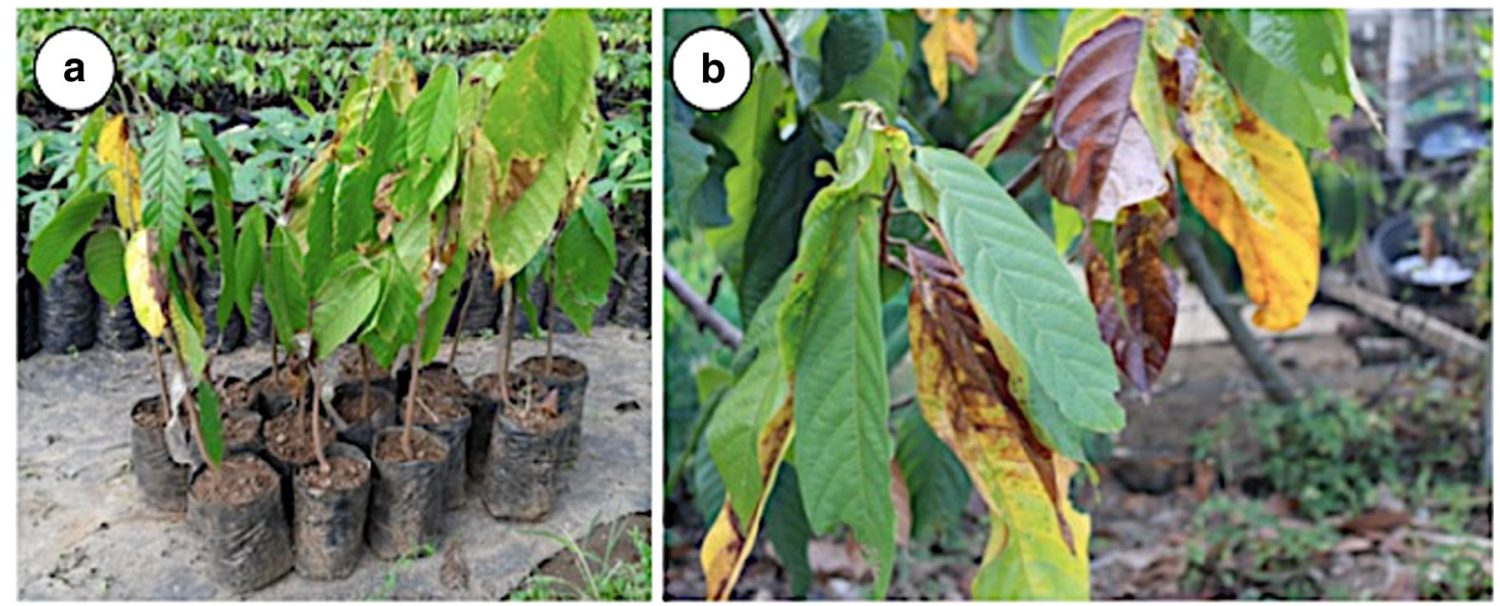

Fig. 1 VSD-like symptoms, on cacao showing leaf chlorosis and necrotic blotches on seedlings (a) and a mature tree (b)

before placing five pieces/plate on the surface of potato dextrose agar (PDA) in $90 \mathrm{~mm}$-diam petri dishes. After 35 days incubation at $25^{\circ} \mathrm{C}$ under a $12 \mathrm{~h}$ light $/ 12 \mathrm{~h}$ dark cycle in an incubator, a pure culture was obtained by direct transfer of an advancing single hyphal tip onto freshly plated PDA using a sterile fine pointed needle. Pycnidia originating from the leaves and/or stems were carefully scraped using a sterile needle, mounted in $2 \%$ lactic acid on a glass slide, covered with a coverslip and examined under a light microscope (Nikon eclipse 50i, Japan) equipped with a camera (Nikon DSFi1, Japan).

The fungus was characterized by intense aerial and fast-growing mycelium filling a 90 -mm-diam petri plate in 3 days at $25{ }^{\circ} \mathrm{C}$. Mycelium became dark with age, with black globose pycnidia developing singly or in groups, with or without stroma, with central ostioles that were observed after 14 days of incubation at $25{ }^{\circ} \mathrm{C}$. Conidia were initially unicellular, ellipsoidal, hyaline, thick-walled with granular content, and 25-27 × 11-13 $\mu \mathrm{m}$. Mature conidia were one-septate, dark brown and with longitudinal striations (Fig. 4). The morphology of the fungus assessed in this study matched well with that described for L. theobromae by Burgess et al. (2006) Taylor et al. (2005) and Sutton (1980). The pure culture of the $L$. theobromae was deposited in the Philippine National Collection of Microorganism, National Institute of Molecular Biology and Biotechnology (BIOTECH), University of the Philippines Los Baños, Laguna with Accession number 3443.

To initiate pathogenicity studies, the fungus was grown under light at $25{ }^{\circ} \mathrm{C}$ for 4 weeks on PDA plates supplemented with $1 \mathrm{~g}$ of $\mathrm{K}_{2} \mathrm{HPO}_{4}$ (Ekundayo 1973). Thereafter, $5 \mathrm{~mL}$ of sterile 1/4-strength Ringer's solution (Daigo, Tokyo, Japan) were flooded onto petri dishes to maintain the osmotic balance
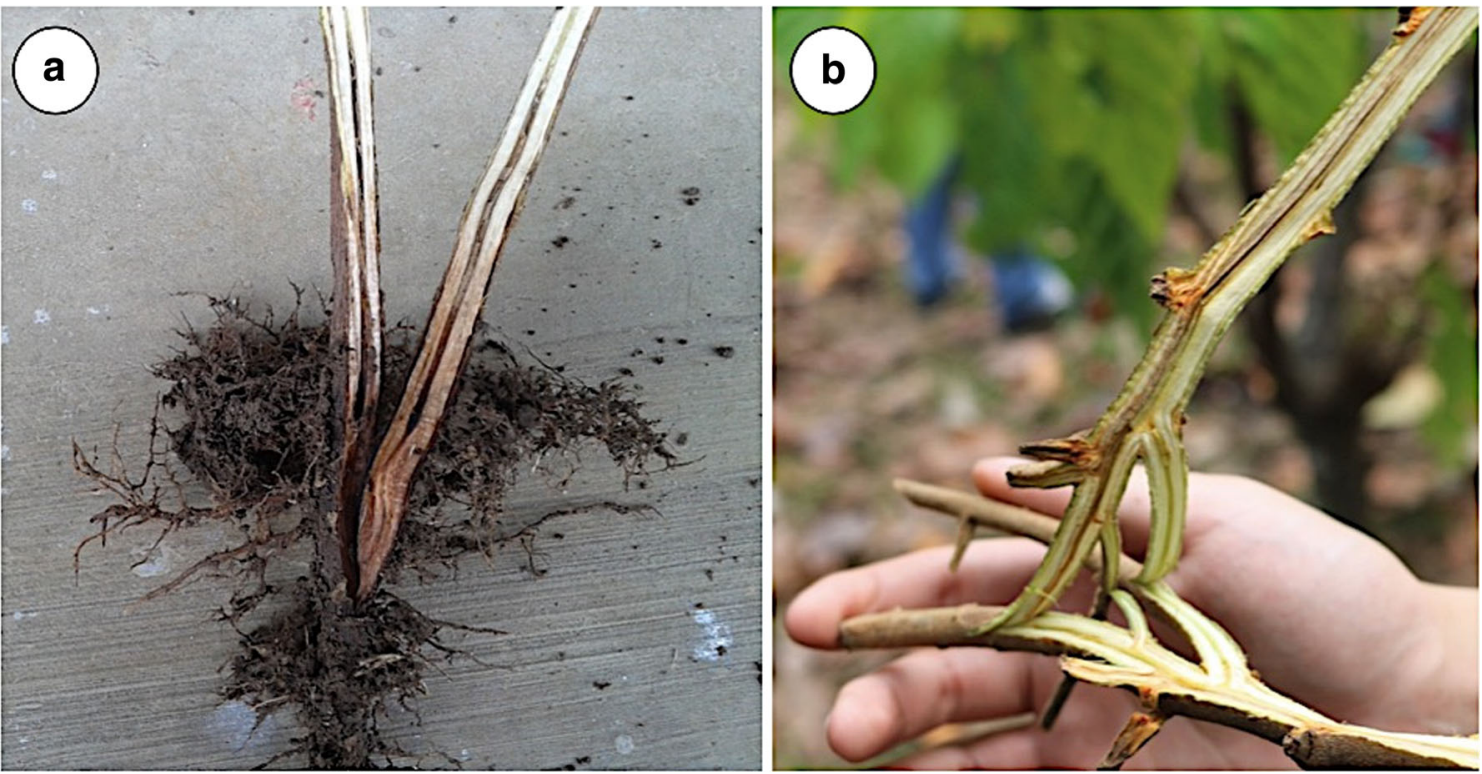

Fig. 2 VSD-like symptoms, on cacao showing visible dark streaks within the vascular tissue on an infected seedling (a) and a mature tree (b) 
Fig. 3 VSD-like symptoms, on cacao three discolored vascular traces at the base of a fallen diseased leaf (pointed by arrows) with enlarged lenticels on the bark (enclosed in circles)

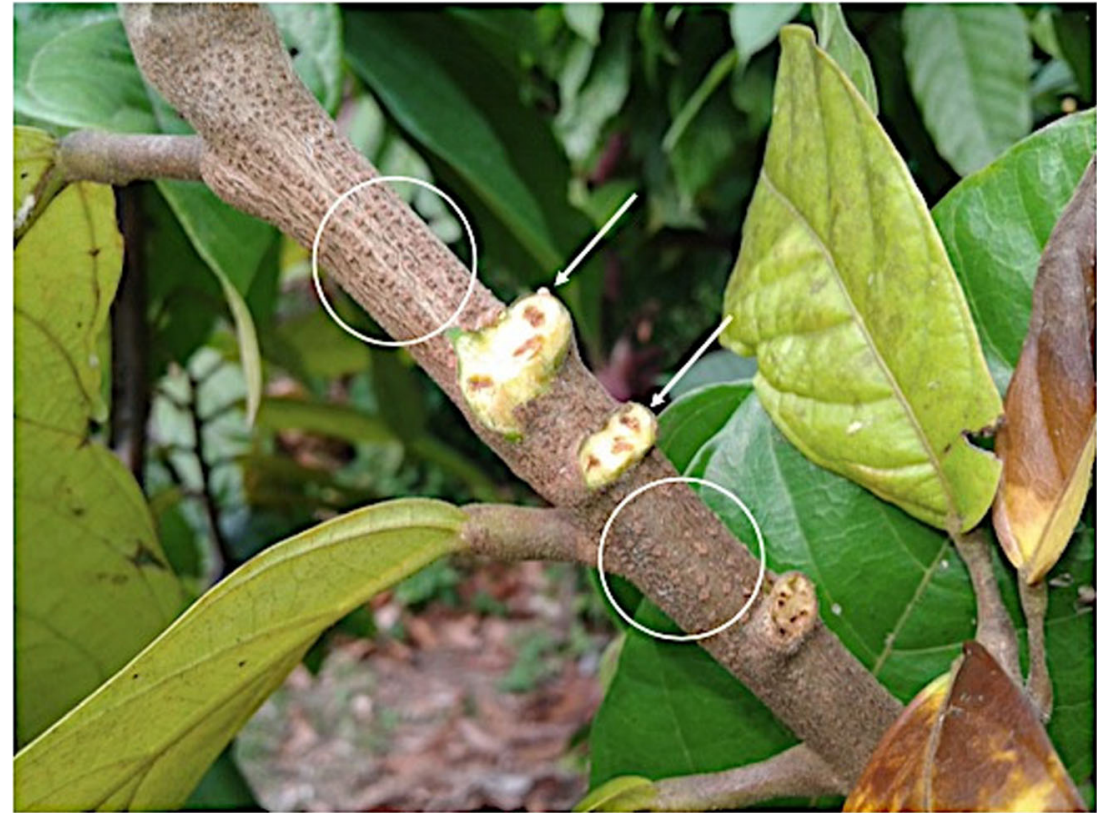

of the fungus. Ringer's solution was composed of $\mathrm{NaCl}$ $(2.25 \mathrm{~g}), \mathrm{KCl}(0.105 \mathrm{~g}), \mathrm{CaCl}_{2}(0.12 \mathrm{~g})$ and $\mathrm{NaHCO}_{3}$ $(0.05 \mathrm{~g})$ per litre of distilled water. (www.sigmaaldrich.com/ catalog/product/sial/96724?lang=en\&region=PH). The surfaces of the flooded colonies were gently stirred using a sterile glass rod to dislodge conidia then the suspension was filtered through sterile four layers of cheese cloth to separate the spores from mycelium and agar. The concentration of the spore suspension was adjusted to $10^{6}$ spores $/ \mathrm{mL}$ with the aid of a haemacytometer (Hausser, Horsham, PA, USA). Pathogenicity was tested three times between 2015 and 2016 on 10 healthy 3-month-old seedlings growing in pots in a net house at the nursery of CocoaPhil, Talandang, Davao City. The spore suspension was sprayed until runoff onto young intact apical leaves using a hand held atomiser. The entire seedling was wrapped with an internally wet plastic bag immediately after spraying to maintain a high level of humidity. The plastic bag was removed after $72 \mathrm{~h}$ and plants observed weekly for the appearance of VSD-like symptoms. Symptoms very similar to those observed in the nursery such as leaf chlorosis/necrosis, vascular browning and lenticel swelling were found on the inoculated plants 10 weeks after spray inoculation. Control leaves remained symptomless. A fungus with the same morphology as described above was found growing on the infected leaves and stems and was isolated in pure culture using the methods outlined above. The cultures had morphological features identical to those generated from the field plants with VSD-like symptoms, thus fulfilling Koch's postulates.

Mycelia grown on PDA at $25^{\circ} \mathrm{C}$ were harvested after $1-$ 2 weeks. Genomic DNA was extracted from cultured mycelium an ISOLATE II Genomic DNA Kit (Bioline, MA, USA). The nuclear ribosomal internal transcribed spacer (ITS) region was amplified with primer pairs ITS 1 ( $5^{\prime}-\mathrm{TCCG}^{-}$ TAGGTGAACCTGCGG-3') forward direction and ITS4 (5'-TCCTCCGCTTATTGATATGC-3') reverse direction
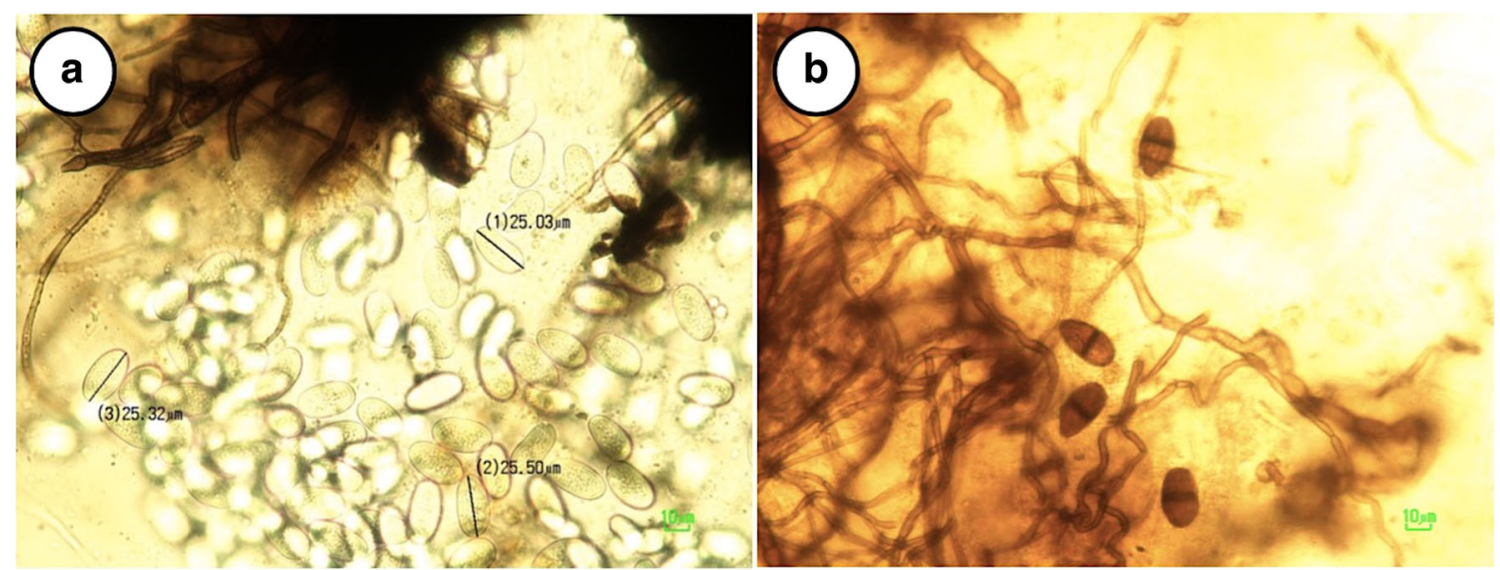

Fig. 4 Morphology of Lasiodiplodia theobromae under light microscopy showing immature (a) and mature conidia (b) 
(White et al. 1990). Polymerase chain reaction (PCR) amplification of ribosomal DNA (rDNA) was performed with 34 cycles of incubation for $5 \mathrm{~min}$ at $94{ }^{\circ} \mathrm{C}, 45 \mathrm{~s}$ at $94{ }^{\circ} \mathrm{C}, 30 \mathrm{~s}$ at $66{ }^{\circ} \mathrm{C}$, and $60 \mathrm{~s}$ at $72{ }^{\circ} \mathrm{C}$. Titanium ${ }^{\circledR}$ Taq DNA Polymerase (Clontech, CA, USA) was used for gene amplifications. Sequencing was made by 1 st Base, Singapore (www.baseasia.com/dna-sequencing-services). Sequence alignment and homology analysis were carried out using Gblocks server (Castresana 2000). The aligned sequence was analyzed by Neighbor-Joining @ PAUP 4.0b10 (Swofford and Sullivan 2009). The distance matrix was calculated using BLAST (http://blast.ncbi.nlm.nih.gov/Blast.cgi) which compared the nucleotide sequences of our unknown fungal isolate to the sequence database. A BLAST search of the GenBank database revealed that the sequence of the fungus from causing VSD-like symptoms in Davao region had a $100 \%$ homology with $L$. theobromae Aravind Mdu India LT407. Diagnostic sequences were submitted to the Research Organization of Information and Systems, National Institute of Genetics, DNA Data Bank of Japan (DDBJ) with Accession number LC275062.

In Papua New Guinea (PNG) in the early 1960s, a serious dieback disease, given the name "Botryodiplodia dieback," was attributed to infection by $L$. theobromae, which was regularly isolated from diseased specimens (Shaw 1962; Bridgeland et al. 1966), weakened stems and branches suffering tip dieback (McMahon and Purwantara 2016). Moreover, L. theobromae was reported causing a damaging dieback of cocoa in India (Kannan et al. 2010), Cameroon (Mbenoun et al. 2008) and Western Samoa (Bourke 1992).

This paper is the first report of $L$. theobromae as the causal agent of a VSD-like disease of cacoa in Talandang, Davao City, Philippines. It is likely that several other fungal pathogens of the disease in cacao could also exist in the Philippines but have, so far, remained unreported. VSD-like symptoms caused by $L$. theobromae has a considerable impact on cacao production in the Philippines and we have started to manage the disease through the development of a "biological-based approach" through isolation and screening of microbial antagonists as biocontrol agents.

Acknowledgements The authors gratefully acknowledge the Philippine Council for Agriculture, Aquatic, and Natural Resources Research and Development-Department of Science and Technology (PCAARRD-DOST) for the financial support.

\section{References}

Bourke TV (1992) Pests and diseases of cocoa in Western Samoa and the Philippines. In: Keane PJ, Putter CAJ (eds) Cocoa pest and disease management in Southeast Asia and Australia. FAO Plant Production and Protection Paper No. 112, Rome, pp 195-198

Bridgeland LA, Richardson JM, Edwards IL (1966) Dieback diseases of cacao (Part 1). South Pacific Planter 1:13-20

Burgess TI, Barber PA, Mohali S, Pegg G, de Beer W, Wingfield MJ (2006) Three new Lasiodiplodia spp. from the tropics, recognized based on DNA sequence comparisons and morphology. Mycologia 98:423-435

Castresana J (2000) Selection of conserved blocks from multiple alignments for their use in phylogenetic analysis. Mol Biol Evol 17:540-552

Ekundayo JA (1973) Nutrient requirements for production of pycnidia of Botryodiplodia theobromae Pat. J Gen Microbiol 77:227-228

Guest DI (2007) Black pod: diverse pathogens with a global impact on cocoa yield. Phytopathology 97:1650-1653

Guest DI, Keane PJ (2007) Vascular-streak dieback: a new encounter disease of cacao in Papua New Guinea and Southeast Asia caused by the obligate basidiomycete Oncobasidium theobromae. Phytopathology 97:1654-1657

Kannan C, Karthik M, Priya K (2010) Lasiodiplodia theobromae causes a damaging dieback of cocoa in India. Plant Pathol 59:410

Mbenoun M, Momo Zeutsa EH, Samuels G, Nsouga Amougou F, Nyasse S (2008) Dieback due to Lasiodiplodia theobromae, a new constraint to cocoa production in Cameroon. Plant Pathol 57:381

McMahon P, Purwantara A (2016) Vascular streak dieback (Ceratobasidium theobromae): history and biology. In: Bailey BA, Meinhardt LW (eds) Cacao diseases: a history of old enemies and new encounters. Springer, Cham, pp 307-335

Samuels GJ, Ismael A, Rosman A, Junaid M, Guest DI, McMahon PJ, Keane PJ, Purwantara A, Lambert S, Rodriguez-Carres M, Cubeta MA (2012) Vascular streak dieback of cacao in Southeast Asia and Melanesia: in planta detection of the pathogen and a new taxonomy. Fungal Biol 116:11-23. https://doi.org/10.1016/j.funbio.2011.07. 009

Shaw DE (1962) Diseases of cacao in Papua New Guinea. Papuan New Guinea Agric J 15:79-90

Sutton BC (1980) The coleomycetes: fungi imperfecti with pycnidia, acervuli and stromata. CMI, Surrey $696 \mathrm{p}$

Swofford D, Sullivan J (2009) Phylogeny inference based on parsimony and other methods using PAUP*. In: Lemey P, Salemi M, Vandamme AM (eds) The phylogenetic handbook: a practical approach to phylogenetic analysis and hypothesis testing. Cambridge University Press, Cambridge

Taylor A, Hardy GESJ, Wood P, Burgess T (2005) Identification and pathogenicity of Botryosphaeria species associated with grapevine decline in Western Australia. Australas Plant Pathol 34:187-195

White TJ, Bruns T, Lee S, Taylor J (1990) Amplification and direct sequencing of fungal ribosomal RNA genes for phylogenetics. In: Innis MA, Gelfand DH, Sninsky JJ, White TJ (eds) PCR protocols: a guide to methods and applications. Academic, San Diego, pp 315-322 